\title{
Information-algorithmic basis of a program complex for forest fire danger estimation
}

\author{
Marina V. Engel ${ }^{1}$, Vladimir V. Belov ${ }^{1,2}$, Nikolay V. Baranovskiy* ${ }^{3}$, Elena P. Yankovich ${ }^{3}$, \\ ${ }^{1}$ Institute of Atmospheric Optics SB RAS, 1 Academician Zuev square, Tomsk, Russia, 634055 \\ ${ }^{2}$ National Research Tomsk State University, 36 Lenin av., Tomsk, Russia 634050 \\ ${ }^{3}$ National Research Tomsk Polytechnic University, 30 Lenin av., Tomsk, Russia 634050
}

\begin{abstract}
Present work is devoted to the description of information and algorithmic support for creation of a program complex for an assessment of forest fire danger. The assessment of forest fire danger is made on the basis of algorithm for classification of the forest territory by vegetation conditions and the modified Nesterov's index. Meteorological data (air temperature and cloudiness) and also the data on thermal anomalies received from satellite measurements by MODIS spectroradiometer for the territory of the Timiryazevskiy forestry of the Tomsk region are used as information on the Environment state.
\end{abstract}

Keywords: sunlight, forest fire, danger, assessment, remote sensing, MODIS

\section{Introduction}

Development of up-to-date information and satellite technologies creates conditions for improvement of methods and approaches for assessment, monitoring and forecasting of forest fire danger, especially on large forested territories. The majority of widely used valuation methods of forest fire danger are deprived of physical sense and are based on statistical data for the long period across the specific territory [1]. Such approach often leads to errors, especially at sharp climatic changes (for example, forest fires during 2010 year in the Central Russia and during 2012 year in the Tomsk region). Moreover, a vital issue is availability of meteorological data on the controlled territory as the zone of responsibility of definite meteorological station is great. It does not allow to carry out a precision assessment of the forest fire danger on the defined forested territory. The significant progress can achieve when we are using satellite data of MODIS device [2].

The work purpose is creation of software module for remote sensing data preparation as a part of a geographic information system for assessment of forest fire danger.

\section{Mathematical Model}

The probabilistic criterion allow to estimate predisposition of the forested territory to occurrence of forest fires as a result of influence of the focused sunlight is developed for an assessment of forest fire danger level [3-5]:

$$
\begin{aligned}
& P(N)=P(M) P(I / M), \\
& P(M)=\frac{C M I_{c u r}}{C M I_{\max }}, \\
& P(I / M)=k_{c} \frac{N_{F S}}{N_{T S}},
\end{aligned}
$$

*firedanger@narod.ru, phone +7-903-953-56-95, tpu.ru

22nd International Symposium Atmospheric and Ocean Optics: Atmospheric Physics, edited by

Gennadii G. Matvienko, Oleg A. Romanovskii, Proc. of SPIE Vol. 10035, $100353 Z$

(C) 2016 SPIE · CCC code: 0277-786X/16/\$18 - doi: 10.1117/12.2249125 
$C M I=k_{p} \sum_{i=1}^{N} T_{e}\left(T_{e}-r\right)$,

Where $\mathrm{P}(\mathrm{N})$ - probability of predisposition of the territory and favorable weather conditions for occurrence of forest fires; $\mathrm{P}(\mathrm{M})$ - probability of favorable weather conditions for occurrence of forest fires; $\mathrm{P}(\mathrm{I} / \mathrm{M})$ - conditional probability of forest fuel ignition at favorable weather conditions;

CMI - complex meteorological indicator (Nesterov's index); $\mathrm{k}_{\mathrm{p}}$ - coefficient of precipitation; $\mathrm{T}_{\mathrm{e}}-$ air temperature; $\mathrm{r}-$ dew point temperature; $k_{c}$ - coefficient of cloudiness; $N_{F S}-$ number of fire-dangerous sites in a quarter; $N_{T S}-$ total number of sites in a quarter. Indexes: cur (current) index - the current value of an indicator, max - the maximum value of an indicator, $\mathrm{p}$ (precipitation) - rainfall, e (environment) - parameters of environment, c (cloud) - cloudiness, FS (fire sites) - fire-dangerous site, TS (total sites) - total sites.

\section{Technological solutions}

To solve a problem of forest fire danger assessment on the basis of probabilistic approach and the modified Nesterov's index assumes using of data on parameters of optical-meteorological conditions of the atmosphere. Up-to-date satellite methods of diagnostics of the environmental parameters allow to remove a question about efficiency of data and to provide rather high spatial resolution of the restored data, comparable with spatial resolution of satellite radiometric channels.

It is offered to use satellite data on vertical profiles of temperature and humidity and cloudiness parameters and also the data on thermal anomalies received from measurements of MODIS/EOS spectroradiometer in this work. For this purpose the following thematic MODIS products are of interest:

- MxD07_L2 - profiles of temperature and water vapor (geopotential, temperature, dew point temperature; the integrated content of ozone, integrated moisture content) and the cloudy mask, nominal permission makes $5 \mathrm{~km}$ $[2,6]$

- MxD14_L2 - the temperature anomalies obtained as a result of algorithm implementation of fires detecting [2].

It should be noted that thematic MODIS products have an important assessment of quality of the restored QA values (QA - quality assessment or quality assurance) [7].

According to satellite data and solutions of the inverse problems connected with it two basic approaches are developed for restoration of vertical profiles of meteorological parameters (physical and regression). Owing to complexity and computing labor input of the first method for mass processing of satellite measurements in practice the "fast" statistical technique where required meteorological parameters of the atmosphere are connected with satellite measurements within system of the linear regression equations [8] is used. Some data on the accuracy of this method according to which the mean square error of restoration of profiles of low layer atmosphere temperature lies within $2 \mathrm{~K}$ and humidity about 10$15 \%$, and with growth of height of an error decrease are submitted in work [9].

So-called "cloudy mask" is an integral part of a solution of various tasks on the basis of satellite data. With its help the pixels of the satellite image closed by dense cloudiness where the solution of a problem for restoration of environmental parameters is impossible are selected.

The method for detecting a cloudy mask on satellite measurements is based on that known fact that clouds, as a rule, have higher reflection ability and lower temperature in comparison with a land surface. Therefore by means of simple threshold tests in channels of visible and infrared ranges of a range it is possible to estimate existence of cloudiness in pixel of the satellite image with a certain probability. Results of works on validation of a method of cloudiness detection [10], showed that the error of cloudiness detecting makes about $15-20 \%$.

For the purpose of determination of applicability in scientific researches of thematic atmospheric products of MODIS works on validation of these data at the regional level [11] which in general confirmed the estimates of accuracy of restoration of parameters given by authors of algorithms were carried out to Institute of Atmospheric Optics SB RAS for a number of years.

The algorithm for detecting of thermal anomalies using MODIS Fire Products is intended for global monitoring of forest fire according to satellite EOS/MODIS system and is widely used as abroad, and within the Russian systems of a remote sensing of forest fires of various levels. This algorithm includes the following stages:

1) construction for the image of "cloudy" mask and "water" pixels;

2) determination of potential "hot" pixels;

3) calculation of "background" characteristics in a neighborhood of "hot" pixels; 
4) application of decisive rules and contextual tests for detecting of the centers;

5) rejection of false alarms;

6) assessment of reliability of fire detection.

HDF format (Hierarchical Data Format) and the HDF-EOS format developed for representation of thematic MODIS products on its basis which has all opportunities of an initial format is used, and also includes models of geospatial and temporary data. The model called by Scientific Data Set (SDS), intended for storage of multidimensional matrixes is the cornerstone of the concept of HDF.

Special software was developed for work with HDF/HDF-EOS formats allowing to carry out a choice and unpacking of the SDS sets in the resulting text file which can be used as basic data for a probabilistic assessment of forest fire danger at creation of a geographic information system. The fragment of the file received as a result of unpacking of a thematic product of the MOD07L2 type is given in table 1. № values of a line' and '№ a column' correspond to the provision of pixel in an initial matrix, the latitude and longitude of a point of measurements register further in earth surfaces, temperature and height of a ground layer, value of a cloudy mask.

Table 1. Fragment of the typical file with results of program algorithm implementation

\begin{tabular}{|c|c|c|c|c|c|c|}
\hline № raw & $\begin{array}{l}\text { № } \\
\text { column }\end{array}$ & latitude & longitude & temperature & height & cloud mask \\
\hline 41 & 123 & 55,966 & 84,986 & 290,76 & 134 & \\
\hline 41 & 124 & 55,955 & 84,907 & 290,1 & 118 & \\
\hline 41 & 125 & 55,945 & 84,828 & 290,11 & 122 & \\
\hline 42 & 123 & 56,01 & 84,967 & 290,97 & 134 & \\
\hline 42 & 124 & 56 & 84,888 & 290,4 & 97 & \\
\hline 42 & 125 & 55,989 & 84,809 & 290,7 & 133 & \\
\hline 42 & 126 & 55,978 & 84,73 & 290,4 & 151 & \\
\hline 42 & 127 & 55,967 & 84,651 & 290,43 & 165 & \\
\hline 42 & 128 & 55,956 & 84,572 & 290,73 & 179 & \\
\hline 42 & 129 & 55,945 & 84,494 & 290,88 & 187 & \\
\hline 43 & 123 & 56,053 & 84,942 & 289,63 & 94 & \\
\hline 43 & 124 & 56,042 & 84,862 & 289,99 & 106 & \\
\hline 43 & 125 & 56,032 & 84,783 & 290 & 148 & \\
\hline 43 & 126 & 56,021 & 84,704 & 290,09 & 161 & \\
\hline
\end{tabular}

LAADS Web resource and also a distributed infrastructure of Remote Sensing Collective Data Center of the Siberian Branch of the Russian Academy of Science and electronic archives of satellite data from Institute of Atmospheric Optics of the Siberian Branch of the Russian Academy of Science are considered as sources of thematic MODIS products containing optical-meteorological parameters and results of fire detecting.

\section{Results and Discussion}

Spatial modeling system ArcGIS was chosen as host-system for development of geoinformation system for estimation of forest fire danger caused by focused sunlight action estimation. Autonomous table with characteristics of forest quarters and plots is created in geodatabase in this system. The following data is necessary for forest fire danger estimation according to technique [4,12]: quarter number, site number, species structure of forest area, age of a forest stand on this site. This data can be taken from standard books of forest taxation descriptions. Timiryazevskiy forestry of the Tomsk region is chosen as territory on which forest fire danger estimation and control is planned.

By means of built-in ArcGIS ModelBuilder interface the model which includes the built-in tools of data processing and the program scripts written in built-in language of the specialized software (high level language Python) is created for calculation of probability of forest fire occurrence caused by focused sunlight action. The general scheme of data processing is presented in Fig. 1. 


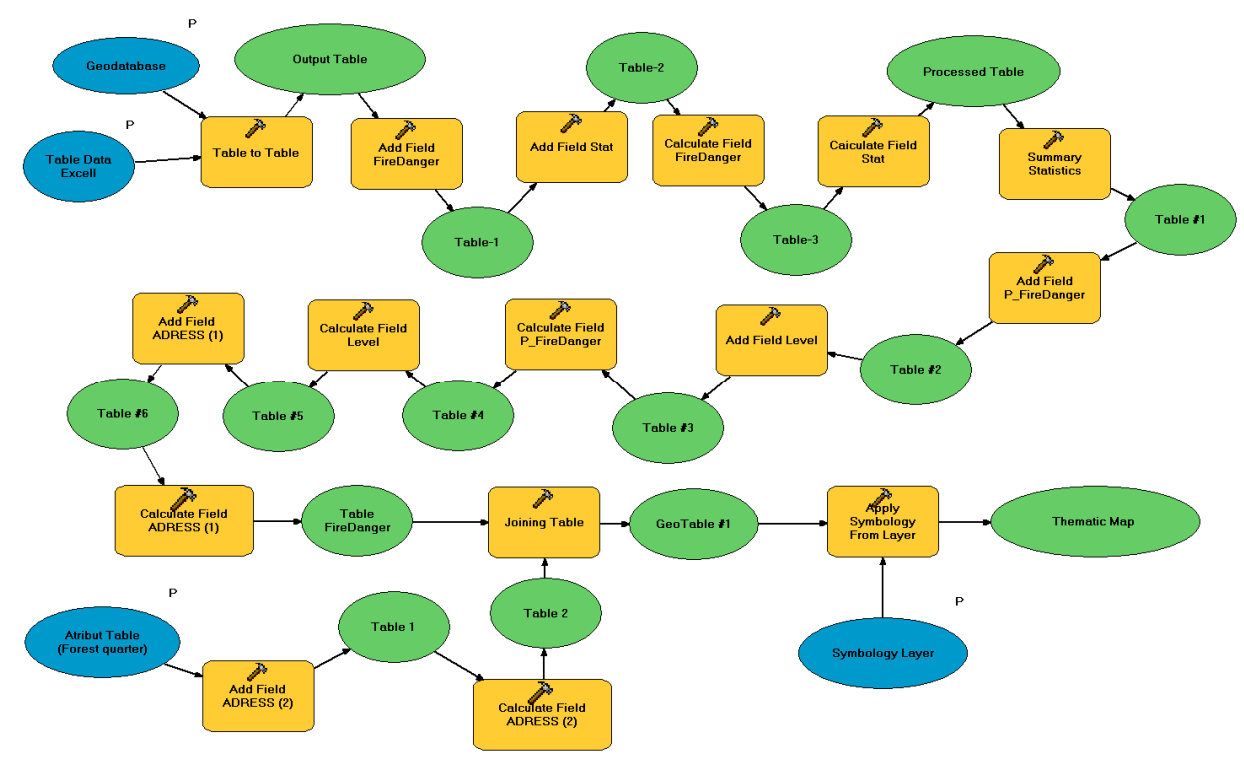

Figure 1. Data processing in GIS-system

It is necessary to notice that among possible representations: tables, diagrammes or electronic maps, the latest are the most appropriate for graphic display of results of forest fire danger estimation (not only caused by focused sunlight action). Presence in the host-program (specialized software) tools of the built-in programming, such as, Python script language, allows developing more advanced and functional geographical information systems. Typical electronic map with information about forest fire danger level is presented in Fig. 2.

There is a calculation of probability of favorable weather conditions for occurrence of forest fires using formula (2) at the first stage. The maximum and current value of Nesterov's index is estimated according to formula (4). The conditional probability of forest fuel ignition at favorable weather conditions is defined according to a technique [13] with cloudiness (cloudiness coefficient $\mathrm{k}_{\mathrm{c}}$ is offered in the present work). Probability of predisposition of the territory and favorable weather conditions for occurrence of forest fires will allow to estimate quantitatively the level of the forest fire danger caused by the focused sunlight.

The analysis of space distribution of forest fire danger probability across the territory of the Timiryazevskiy forestry shows that for June 17, 2012 danger level in the focused sunlight conditions was minimum on major part of the territory. The main impact on the value of probability of forest fire occurrence is had not only cloudiness, but also meteorological factors, for example, precipitations and temperature. These parameters are considered at calculation of Nesterov's index. It should be noted that there are various approaches to calculate the Nesterov's index regarding the accounting of precipitation. It agrees [14], the sum is nullified at $3 \mathrm{~mm}$ of rainfall. In too time, authors [15] offer the differentiated assessment of influence of rainfall on the value of Nesterov's index, using zeroing at $20 \mathrm{~mm}$ of rainfall.

A variety of methods and approaches to the accounting of rainfall demands the comprehensive analysis of this problem in the context of an assessment of forest fire danger, including, with use of data of remote sensing of Earth and the atmosphere from space [16].

\section{Conclusion}

Thus, problem of software module creation for data preparation of remote sensing as a part of a geographic information system for assessment of forest fire danger is solved as a result of the present work. Approbation of algorithms is carried out across the territory of the Timiryazevskiy forestry of the Tomsk region.

Using of such systems in the field of forest protection from fire should promote more rational use of the means selected for protection of large forests. Speaking about forest fire danger of the Timiryazevskiy forestry it is visible that clustering of fire-dangerous sites in a settlement vicinity Timiryazevskiy is observed. It means that additional means of visual control over fire-dangerous conditions can be used in this district like observant towers with video registration systems, GPS - or GLONASS-navigation [17] and remote access on channels of cellular communication GSM [18]. 


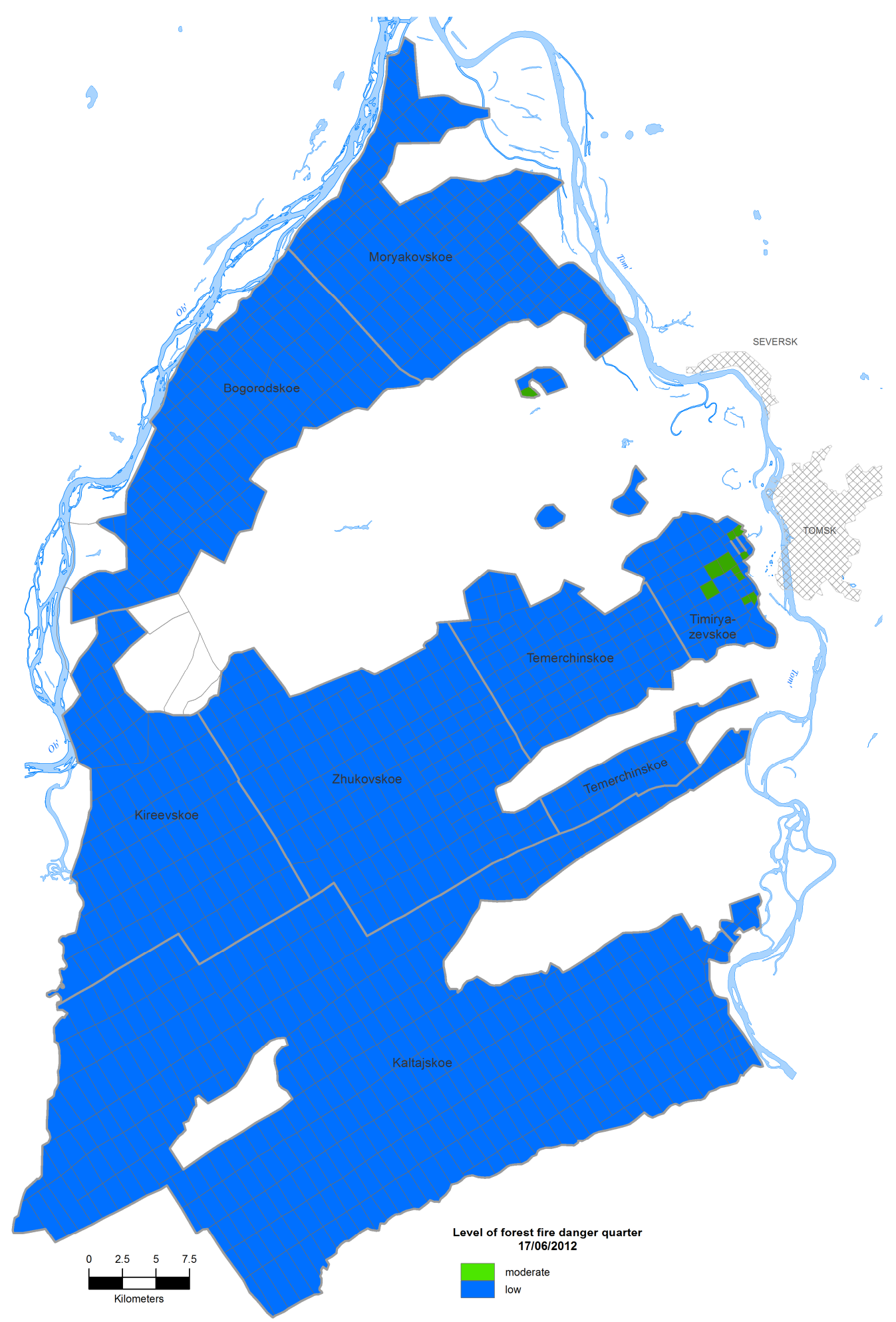

Figure 2. Electronic map of forest fire danger level on territory of the Timiryazevskiy forestry of Tomsk region

Proc. of SPIE Vol. 10035 100353Z-5 


\section{Acknowledgements}

GIS part of information system for forest fire danger assessment is developed under financial support of Ministry of Education and Science within FCP «Researches and developments in priority directions of development of a scientifically-technological complex of Russia on 2007 - 2013». State contract № 14.515.11.0106.

\section{References}

[1] Kuznetsov G.V., Baranovskiy N.V. [Forecast of forest fire occurrence and their ecological consequences]. Publishing house of the Siberian Branch of the Russian Academy of Science, Novosibirsk. 301 P. (2009) (In Russian)

[2] Giglio L., Descloitres J., Justice C., Kaufman Y. "An Enhanced Contextual Fire Detection Algorithm for MODIS", Remote Sens. Environ. 87, 273 - 282 (2003)

[3] Baranovskiy N.V. "Method for forecasting of forest fire danger as basis of new state standard", Fire safety, 4, 80 - 84 (2007) (In Russian)

[4] Kuznetsov G.V., Baranovskiy N.V. "Focused sun's rays and forest fire danger: new concept", Proceedings of SPIE, 8890,889011 (2013)

[5] Baranovskiy N.V., Zharikova M.V. "A Web Oriented Geoinformation System Application for Forest Fire Danger Prediction in Typical Forests of the Ukraine", Lecture Notes in Geoinformation and Cartography - LNG\&C. Thematic Cartography for the Society, 13 - 22 (2014)

[6] Seemann S.W., Borbas E.E., Li J., Menzel W.P., Gumley L.E. "MODIS Atmospheric Profile Retrieval Algorithm Theoretical Basis Document" (2006)

[7] Hubanks, et.al. "MODIS Atmosphere QA Plan for Collection 005 \& 051". Version3.10. (2012)

[8] Seemann S., Li J., Menzel W.P., Gumley L. "Operational retrieval of atmospheric temperature, moisture, and ozone from MODIS infrared radiances", J. Appl. Meteorol, 42, 1072 - 1091 (2003)

[9] Gao B.C., Kaufman Y.J. "Water vapor retrievals using Moderate Resolution Imaging Spectroradiometer (MODIS) of near-infrared channels", J. Geophys. Res. 108, 4389 (2003)

[10] Ackerman S., Strabala K., Menzel P., Frey R., Moeller C., Gumley L., Baum B., Seemann S., Zhang H. "Discriminating clear-sky from cloud with MODIS. MOD35 Algorithm Theoretical Basis Document".Santa Barbara: ICESS, University of California. 124 P. (2006)

[11] Afonin S.V. "Some results of studying of characteristics of an optical status of the atmosphere in Tomsk region according to satellite data of MODIS", Optics of atmosphere and ocean, 18, 400 - 405 (2005) (In Russian)

[12] Baranovskiy N.V., Yankovich E.P. "Geoinformation system for prediction of forest fire danger caused by solar radiation using remote sensing data", Proceedings of SPIE, 9640, 96400Z (2015)

[13] Yankovich, E.P., Baranovskiy, N.V., Yankovich, K.S. "ArcGIS for assessment and display of the probability of forest fire danger", 2014 9th International Forum on Strategic Technology, IFOST 2014, 6991108, 222 - 225 (2014)

[14] Vonskiy S.M., Zhdanko V.N. [Methodical instructions according to degree of dryness of fire-dangerous seasons and to calculation of probability of their approach]. LENNIILKH, Leningrad. 22 P. (1967) (In Russian)

[15] Telitsin G.P. "Method to determinate fire danger of the forest territory", Forest fires and fight against them. VNIILM, Moscow, 13 - 28 (1987) (In Russian)

[16] Baranovskiy N.V., Yankovich E.P. "Geoinformation Monitoring of Forest Fire Danger on the Basis of Remote Sensing Data of Surface by the Artificial Earth Satellite", Journal of Automation and Information Sciences. 47(8), 11 $23(2015)$

[17] Weilin L., X., Yu L. "Application of RS, GPS and GIS to forest management in China", Journal of Forestry Research, 11, 69-71 (2000)

[18] Baumann S., Czaja J., Lechner W. "Improving safety in Alpine Regions through a combination of GSM/GPRS with satellite communications, GIS, and robust positioning technology", Sustainable Natural Hazard Management in Alpine Environments. / Eds. Veulliet E. et al. Springer. 345 - 377 (2009) 